\title{
Explaining and predicting the impact of regulation on innovation: towards a dynamic model
}

\author{
Carlos Montalvo \\ TNO, Netherlands Organization for Scientific Applied Research \\ Schoemakerstraat 97, P.O. Box 6040, 2600JA Delft \\ The Netherlands \\ Fax: +31152695460 \\ E-mail: carlos.montalvo@tno.nl
}

\begin{abstract}
Although much work has been done on the regulation and governance of innovation, it provides few formal analytical tools to enable us to learn about the dynamics of the regulatory system in terms of the interaction between regulators and firms. If governance occurs in a context of mutual interdependence and power asymmetries, governments inevitably find themselves with little independence to design and effectively conduct and enforce governance schemes. This paper aims to fill some of the gaps in the public policy literature by proposing a model to generate and validate behavioural indicators for governance of innovation and policy analysis. The model proposed helps to explore the conditions under which the firm would be more likely to innovate. In addition, it enables us to identify the preconditions determining the willingness and ability of regulators to design and enforce schemes that influence the innovative behaviour of the firm.
\end{abstract}

Keywords: regulation; governance; corporate behaviour; interdependence; power; innovation; 'theory of planned behaviour'; Lotka-Volterra.

Reference to this paper should be made as follows: Montalvo, C. (xxxx) 'Explaining and predicting the impact of regulation on innovation: towards a dynamic model', Int. J. Public Policy, Vol. X, No. Y, pp.000-000.

Biographical notes: Dr. Carlos Montalvo is a Senior Advisor on Strategy and Innovation Policy at TNO. He has extensive industry experience in engineering and in project and product management. He is an authority on technology innovation management and policy. His research output is used by several $\mathrm{PhD}$ students from around the world, to organise and conduct their doctoral research. At TNO, his research activities focus on systemic innovation, evaluation and impact assessment of $\mathrm{S} \& \mathrm{~T}$ programmes, strategic prospective intelligence and the application of behavioural and system dynamics models to explore the interaction between regulation and innovation.

\section{Introduction}

The aim of regulation has traditionally been "the control of a particular situation for the benefit of society" (Rothwell, 1992, p.451). Regulations normally arise as a result of social issues, such as health, safety, Intellectual Property Rights (IPR), pricing practices, quality of products, environmental protection, etc. Stemming from these issues and 
deriving from diverse approaches including economics, sociology, history, geography, psychology, etc., past research has generally focused on justifying whether regulation should exist; how regulation arises (Nowotny, 1989), develops and declines; descriptions and accounts of regulatory developments (Jonas, 1999; Bruneau, 2004; Nowotny, et al., 1989), normative schemas showing how regulation should be (Baldwin and Cave, 1999; Ziegenhagen, 1986); descriptions and proposed strategies for the implementation of regulation (Sparrow, 2000); descriptions of regulatory systems (e.g., Boyer and Saillard, 2002; Vidal, 2002; Aglietta, 2002); descriptions of the positive or negative effects of regulation on competitiveness (OECD, 1985; Greene, 1998; Xu, 1999; Heyes and Heyes, 1999; Stewart, 1994), etc. However, some authors have focused on the potential of regulation to promote innovation, foster competitiveness and create new markets (e.g., Rothwell, 1992; Bourreau and Dogan, 2001; Faulkner and Kent, 2001; Drahos and Maher, 2004; Pavitt, 1998; Dewick and Miozzo, 2002; COM, 2004; Blind, 2004). Governments are seen as the key actors that must provide a regulatory framework to induce innovation in order to gain competitive edge for their economies.

Although the literature referred to above provides much qualitative information about the factors influencing the behaviour of regulators and regulated entities, it does not provide an assessment of the relative importance of individual factors, nor does it explore quantitatively the relationships among the determinants of innovation and change. Progress in this direction has been restricted by a lack of theoretical thoroughness, which restricts the generation of testable hypotheses concerning the drivers of behaviours; and lack of methodological rigor that would enable the testing of such hypotheses. Most of the existing research on regulation is descriptive. Furthermore, it is generally acknowledged that regulation implies interaction and relationships among people and among institutions and that such interaction affects the design and outcomes of the regulations (e.g., Blind, 2004; Baldwin and Cave, 1999). It is therefore somewhat surprising that so little work has been done to provide formal analytical tools to enable learning how the regulatory system actually works in terms of the interaction between regulators and regulatees (e.g., Fenger and Klok, 2001; Sabatier, 1999).

A better understanding of the dynamics of regulation is critical to the design of viable innovation policies. This is specially so in the light of the most recent waves of public utility privatisations, which accompanied economic concentration on diverse sectors of economic activities and globalisation trends. In this new governance context, regulation can be conceptualised as a system of mutually interdependent, reflexive, destabilised and competing institutions (Sand, 1998). Thus, if regulation occurs in a context of mutual interdependence and power asymmetries between regulators and firms, regulators will inevitably be left with little independence to design and enforce governance schemes to best promote innovation and change. The questions here are: What is the relative significance of regulation in the factors affecting innovation? In the face of power asymmetries, in which situations can government intervention via regulation converge towards innovation?

This paper aims to contribute to the literature on public policy and governance, particularly on regulation and innovation, by proposing a behavioural model to explore the interplay among, and determinants of, the behaviours of regulators and firms in specific situations. The approach proposed to explore and explain the dynamics of the regulatory game enables identification of, and differentiation among, the preconditions that determine a firm's willingness to engage in innovation for the creation of new markets. In addition, it takes account of the preconditions that limit and determine the 
ability of regulatory entities to promote and direct innovation and behavioural change in firms. In short, this paper provides a model to explore the limits and capacity of a political system to seek and promote change and innovation. This exploration is based on the assessment of the sources of resistance to change and the interaction among social and economic actors. The paper is organised as follows: Sections 2 and 3 introduce the theoretical basis of the proposed model. Sections 4 and 5 develop the model for both regulators and firms with reference to the governance of innovation. The model is developed on two premises. First, innovation and change is conducted by people, i.e., people embedded in institutional structures; so when we think of organisations' or institutions' behaviours, we are actually referring to the behaviour of groups of people or actors with specific agendas, interests, capabilities, power, etc. Second, the regulatory process does not involve only two players. The model proposed introduces a heuristics to explore and make explicit what factors and actors other than the firms and the regulators might influence regulation and innovation. Sections 6 to 8 introduce a method to explore and test interdependencies and power asymmetries between regulators and firms. Finally, Section 9 discusses the proposed approach and its relevance to the research on the effect of regulation on innovation in diverse areas of innovation studies.

\section{Promoting change and innovation: from goals to actions}

According to Ajzen $(1985 ; 1996)$ and Gollwitzer and Bargh (1996), there is a general agreement among social psychologists that most human behaviour is goal-directed. Thus, discounting contingencies, people are expected to behave according to their intentions, goals or plans. This argument is more likely to be applicable to strategic planning of organisations, as this activity is based on the goals to be achieved (Rotemberg and Saloner, 2000). These goals can be seen as the intention to perform in a specific direction, that is, an organisation's planned behaviour.

In this sense, the first condition for a regulatory entity to engage in the design and implementation of policy or enforcement activities is that these activities need to be contemplated by decisions makers as planned behaviour. Thus, the intent or plan can be considered to be the first predictor of the behaviour of regulatory agencies. Similarly, if a firm engages in a specific behaviour (e.g., merger, alliance, cost cuts, innovative activities, compliance with regulations, etc.) this must first have been deliberated over by decision makers as being strategic or tactical. Thus, 'willingness' or the 'intent' to act can be considered to be the first predictor of the regulator's and firm's behaviour.

Following this line of thought, the basic model adopted to explore and explain the behaviour of regulatory entities and firms is based on a behavioural model, the Theory of Planned Behaviour (TPB). ${ }^{1}$ This theory was designed to understand and predict human social behaviour in specific settings (Ajzen, 1991). Fishbein and Ajzen (1980) postulated that people's intention to perform (or not to perform) behaviour is the immediate determinant of that action. The TPB specifies three major sources of cognition-behaviour inconsistency. The first is a change to the initial intention (plan or goal) before it is executed. The second is people's lack of confidence that attainment of their behavioural goal is under their volitional control. The third source is whether a behavioural expectation formed on the basis of attainment of volitional control that leads to actual goal attainment, is contingent on the relation between people's confidence in their ability 
to exercise control over their own action and the extent to which they actually do control events (Ajzen, 1985). These sources of inconsistencies between cognition and behaviour have been classified and defined as:

- Attitude towards the behaviour (A) - is the degree to which a person has a favourable or unfavourable evaluation or appraisal of the behaviour in question.

- Subjective norm $(\mathrm{N})$ - is a social factor, or the perceived social pressure to perform or not to perform the behaviour.

- Perceived behavioural control (C) - is the perceived ease or difficulty of performing the behaviour and it is assumed to reflect past experience as well as anticipated impediments and obstacles (Ajzen 1991, p.188).

At its most basic explanatory level, the TPB postulates that behaviour is a function of the salient beliefs or information relevant to the behaviour. The nature of these beliefs can be explained by looking at how they are shaped. Generally speaking, we form beliefs about an object (or person, activity, institution, etc.) by associating it with various characteristics, qualities and attributes. Depending on this connotative meaning, automatically and simultaneously, we acquire an attitude towards that object (Ajzen, 1991, p.191). ${ }^{2}$ Similarly, we associate our skills, resources, time, etc., with control over our own and/or others' behaviour. Following the TPB model, three kinds of salient beliefs can be distinguished:

1 Behavioural beliefs - which are assumed to influence attitudes towards the behaviour

2 Normative beliefs - which constitute the underlying determinants of subjective norms

3 Control beliefs - which provide the basis for perceptions of behavioural control.

Within this framework, a specific behaviour is considered to have been explained once its determinants have been traced to the underlying belief system (Ajzen, 1991). The TPB demonstrates that people's behaviour in most situations can be explained and predicted in terms of intentions, attitudes, subjective norms and behavioural control. The theory is well supported by empirical evidence; the model has performed with an explanatory reliability up to $91 \%$ of the variance on behaviour (Ajzen, 1991; Doll and Ajzen, 1992; Ajzen and Krebs, 1994). ${ }^{3}$

\section{Linking beliefs and perceptions to willingness}

In this section, we look at the implications of linking belief systems with willingness, on the explanation and prediction of behaviours in specific settings. In addition, we establish through a single model, the theoretical grounds for linking the behaviour of two or more players in a specific policy arena. The first step towards understanding and explaining a specific behaviour is to define the behaviour clearly. To achieve a clear definition of a specific behaviour, the TPB proposes four criteria to form a behavioural criterion. The first - action - is related to the problem of distinguishing between behaviours and events that may be the outcomes of those behaviours. Behaviour can be defined as single actions and behavioural categories. Single actions are specific behaviours performed by an 
individual (e.g., drawing, reading, writing, calculating, running, etc.), while behavioural categories are composed of a set of single actions (e.g., metal casting, product integration, process design, developing new products or services, etc.). Outcomes are the results of single or behavioural categories (e.g., better product performance, higher organisational flexibility, increased market share, etc.). The second criteria is the target (i.e., object, new routines and organisational arrangements, new product, process or service concepts, etc.) towards which the action is directed. The third is the time when the action should or would occur. The fourth is the context in which the behaviour occurs or is supposed to occur. These four criteria help to generate a behavioural criterion essential for the study of any behaviour (Ajzen, 1991). The behavioural criterion must be the same for the behaviour of interest, for the items assessing willingness to behave and for the items composing the scales in the behavioural domains to be identified.

Similar to Guttman's (1954) principle of contiguity, Fishbein and Ajzen (1975) formulated a principle of compatibility to clarify the conditions under which strong correlation of $\mathrm{A}, \mathrm{N}$ and $\mathrm{C}$ with $\mathrm{W}$ and behaviour can be expected. The principle of compatibility states that measures of $\mathrm{A}, \mathrm{N}, \mathrm{C}, \mathrm{W}$ and behaviour are compatible if they have the same behavioural criterion. That is, they should correlate with one other, and especially to the extent that they address the same behaviour, are directed at the same target, in the same context and at the same time. Compatibility can be established either by aggregating behaviours to elevate the generality of the behavioural measure to that of a general $\mathrm{A}, \mathrm{N}$, and $\mathrm{C}$ (by aggregation), or by measuring $\mathrm{A}, \mathrm{N}$, and $\mathrm{C}$ with respect to the specific behaviour of interest (Ajzen and Krebs, 1994).

In order to predict the innovative behaviour of a firm or regulator, the principle of compatibility is used to predict specific behavioural tendencies in specific contexts. This is achieved by encompassing different levels of explanation for the planned behaviour of a given actor (or organisation) in a policy arena. At the most global level, the behaviour of an organisation is assumed to be determined by its strategic planning or intent. At the next level, its planning is determined by attitudes towards the behaviour, social norms and behavioural control as perceived by its senior managers (or senior officers). At the last level, attitudes, social norms and perceived behavioural control, are explained in terms of beliefs about the consequences of performing (or not performing) the behaviour, about the subjective normative prescriptions of relevant referents and about the perceived control over the behaviour or action. In the final analysis, the behaviour can be explained by reference to the beliefs held by an organisation's managers or high-ranking officers, the trustees of the organisation's strategic vision.

From the above, it can be argued that the model essentially consists of a system of hypotheses linking beliefs with behaviour, where each hypothesis requires empirical verification (i.e., the link between each belief considered and the behaviour of interest). Although from a theoretical point of view, willingness can be expected to determine behaviour, this does not imply that a measure of willingness will always be a good predictor of behaviour. A reliable prediction is contingent on two factors that influence the relationship between willingness and behaviour. The first is the degree of correspondence between an index of willingness and the behavioural criterion, i.e., there must be a high correspondence between action, target, context, and time - elements of behaviour - and willingness. Willingness and behaviour can be expected to correspond only to the extent that their elements are identical, i.e., they share the same criterion (Ajzen, 1988). At this point, it is important to clarify that changing any one of the four 
elements (action, target, context and time) that define behaviour can produce completely different sets of beliefs. This must not be confused with a lack of predictive potential of the model. The predictive potential depends on general or specific measurements of the behavioural predisposition in question. The level of specificity or generality is contingent on the behavioural criterion selected. If we are interested in predicting and understanding a single action (or a behavioural category), directed at a certain target, in a specific context, and at a given time, then the assessment of attitude, social norms and perceived control must correspond to the criteria selected in all of these elements (Fishbein and Ajzen, 1980, p.247).

The second factor is the stability of plans, willingness or intentions over time. Plans can change over time; the longer the time interval, the greater the likelihood that events or new information will produce changes in intentions. Long-term predictions are usually not concerned with the behaviour of an individual but rather with projecting or forecasting behavioural trends in a sample of the population (Ajzen, 1988, pp.92-111). The distinction between predicting behaviour at the individual firm or individual regulatory entity level, and at the aggregate level, is important because aggregated willingness is apt to be much more stable over time than individual willingness (Ajzen, 1988, pp.45-61). There is considerable evidence that even when predictions of individual behaviour are relatively poor, predictions of behaviour based on willingness at the aggregate level are often remarkably accurate (Ajzen, 1991; 1996; Montalvo, 2002; Wehn de Montalvo, 2003).

Following the framework presented above, starting from the notion that goals and intentions predict behaviours, it is proposed that the behaviour of both regulators and firms in specific situations and contexts can be explained in terms of attitudes, social norms and perceived behavioural control mediated by intentions. ${ }^{4}$ More specifically, the paper proposes a method to track back the possible generic determinants of the behaviour of both regulators and firms towards innovation. ${ }^{5}$ Furthermore in Section 7, building on the definition of behavioural criteria and the notion of behavioural outcomes, the model presented in Sections 4 and 5 is further developed to test interdependence and power asymmetries between regulators and regulates.

\section{Understanding the limits of regulatory entities to secure innovation governance}

This section outlines how to explore and explain the behaviour of regulatory entities in specific situations and contexts. It present a series of definitions that enable exploration of the perceived reality of regulators, and proposes hypotheses about how these perceptions and beliefs might affect their engagement in the design and enforcement of governance schemes, and in particular, innovation governance.

\subsection{Regulator's attitudes towards the promotion of innovation}

As defined above, attitude is the degree to which decision makers make a favourable or unfavourable evaluation or appraisal of a specific path of action. Based on this definition, in relation to the behaviour of regulatory entities, the attitude towards a specific regulation is an index of the degree to which the regulator likes or dislikes (approves or disapproves of, agrees or disagrees with, etc.) any aspect of his engagement with policy 
design or enforcement activities. Each behavioural belief links the specific behaviour to an outcome or an attribute that is valued positively or negatively. Thus, it can be expected that regulators will prefer behaviours believed to produce desirable consequences, that accord with the goals of the regulatory institutions or the regulators themselves. The attitude towards the behaviour results from the accumulated connotative load associated with the salient behavioural beliefs or relevant information regarding the implications and expected outcomes of the regulation.

Examples of negative attitudinal beliefs concerning the promotion of innovation are: the enforcement of this bill will be highly unpopular; the economic outcome of this regulation is likely to be negative; and the state-of-the-art is not mature, thus the technological and economic risks are high. Such beliefs imply negative connotations for negative outcomes. These negative beliefs can be expected to contribute to the adoption of a negative attitude towards any specific policy design or, in consequence, its enforcement. A negative attitude is likely to prevent any engagement in enforcement (or policy design) activities. However, the perception of positive outcomes can be expected to produce a positive attitude (e.g., innovations can make firms more competitive and foster economic performance, etc.). The beliefs that determine attitude are assumed in general to arise from the perceived social benefits and risks to the public interest that regulation (or policy) would imply, and the perceived political benefits and risks that would accrue to the regulator.

An index of the attitude $\left(A_{R}\right)$ of regulators towards a specific regulation (or policy) in relation to a particular innovation (or set of innovations) can be obtained, as shown in Equation (1), by multiplying the subjective evaluation $\left(e_{r i}\right)$ of each belief attribute and the strength $\left(r_{r i}\right)$ of each salient belief, with the resulting products summed over $n$ salient beliefs:

$$
A_{R} \propto \sum_{i=1}^{n} b_{i r}, e_{i r}
$$

where:

$$
\begin{aligned}
A_{R}= & \text { is the regulator's attitude toward the regulation (or policy) towards } \\
& \text { innovation } \\
b_{i r}= & \text { is the belief (subjective probability) that the regulation (or policy) will lead } \\
& \text { to outcome } i \\
e_{i r}= & \text { is the evaluation of outcome } i \text { by regulator } r \\
\propto= & \text { indicates proportionality between the sum of the } r_{r i} e_{r i} \text { product and a direct } \\
& \text { measure of attitude } \\
\Sigma= & \text { is the sum of the products of } n \text { salient behavioural beliefs and subjective } \\
& \text { probabilities or likely outcomes. }
\end{aligned}
$$

\subsection{Regulator's social norms towards regulation}

As defined above, the subjective norm is an index of the importance that people give to their significant referents (e.g., individuals, groups, or organisations) and whether they are perceived to approve or disapprove of the behaviour in question. In the case of the behaviour of regulatory entities, the subjective norm can be conceptualised as the social pressure or social norm that arises from the context in which the institution (or the 
regulator) operates. Here, we can define the regulatory entity's perceived social norm $\left(N_{R}\right)$ as the importance that the regulator gives to different crucial referents to engage or not in a specific policy design, its implementation or enforcement. The regulator's perceived social norm arises from the accumulated connotative load of its normative beliefs. For example, internal referents, which in a particular situation might be pushing for or against a policy or regulation, are staff suggestions, organisational internal lobbying, administrative and budgeting goals, partisan political agendas, etc. Examples of external referents are the perceptions and expectations of the local community and the wider public, the electorate's voting preferences, legal mandates and requirements, industry lobbying, etc. This construct - i.e., the perceived social norm - makes explicit that in the long run, regulation is never a game between two players. In this way, the role of other players is explicitly introduced into the modelling.

An index of the regulators' perceived social pressure towards the promotion of innovation production can be calculated by multiplying the strength of each normative belief $\left(n_{r j}\right)$ by the regulator's motivation (or perceived necessity) to comply with or follow the referent in question $\left(m_{r j}\right)$. The social norm is hypothesised to be directly proportional to the sum of the resulting products across $n$ salient beliefs, as shown in Equation (2).

$$
N_{R} \propto \sum_{j=1}^{n} b_{r j} m_{r j}
$$

where:

$$
\begin{aligned}
N_{R}= & \text { is the regulator's perceived social norm } \\
b_{r j}= & \text { is the regulator's normative belief concerning referent } j \\
m_{r j}= & \text { is the regulator's motivation to comply with, follow or anticipate the } \\
& \text { preferences of referent } j .
\end{aligned}
$$

It is hypothesised that those regulators that in general perceive high social pressure in favour of certain innovations will be more prone to implement or enforce the required policies, as these are perceived as necessary to maintain their public legitimacy and perhaps secure the future of their agency. However, such a perception may or may not reflect what the important referents really expect from, or think about, the behaviour of the regulatory entity, or even reflect the real situation of the regulatory game.

\subsection{Control over the process of promoting technical and behavioural change}

Perceived behavioural control as defined above is the perceived ease or difficulty of performing the behaviour itself. This index differentiates between behaviours that are under volitional control and those that are not. In the governance context, 'to regulate' or direct the behaviour of specific groups (of organisations or individuals) can be considered behaviour, which in many cases is not under the volitional control of the regulatory entity. The perceived control over any regulatory (or policy-making) process $\left(C_{R}\right)$ is an index of the presence or absence of the requisite resources and opportunities to promote technical and behavioural change in the interests of the promotion of innovation. The beliefs held by regulators may be based on past experience, second-hand information, or any other factors that increase or reduce the perceived difficulty or feasibility of 
implementing a specific policy or regulation. Depending on the perceived organisational, institutional and technological capabilities that the regulatory agency might hold and their perceived control (or influence) over the internal institutional or organisational change on the part of the firm, the willingness of the regulatory agency to enforce a policy can be expected to be strong or weak. Overall, perceived control over the regulation process arises from the accumulated connotative load of beliefs with regard to the perceived ease or difficulty of achieving the planned regulatory (or policy) outcome.

An index of the perceived control over the regulatory process can be estimated by multiplying the control belief strength $\left(c_{r i}\right)$ by the perceived power $\left(p_{r i}\right)$ over the specific factors that facilitate or inhibit the development of implementation of a regulation (or policy). The resulting product is summed across the $n$ salient beliefs as shown in Equation (3).

$$
C_{R} \propto \sum_{i=1}^{n} c_{r i} p_{r i}
$$

where:

$C_{R}=$ is the regulator's perceived control over the regulatory process

$c_{r i}=$ is the control belief strength of the regulator

$p_{r i}=$ is the perceived power over the particular factors that facilitate or inhibit the enforcement of a policy or regulation to promote innovation, as perceived by the regulator.

Finally, in order to integrate the above constructs, Equation (4) suggests that the strategic or tactical intent of the regulatory entity to promote innovation is a function of the three indexes introduced above: $:^{6-7}$

$$
R \sim W_{R}=w_{1}+w_{2} A_{R}+w_{3} N_{R}+w_{4} C_{R}
$$

where:

$R=$ is the overt behaviour, the engagement of the regulatory entity in policy development or the enforcement of specific regulation towards the promotion of innovation

$W_{R}=$ is the willingness, plan or intention to engage in the enforcement

$A_{R}=$ is the regulator's attitude toward engagement with enforcement activities

$N_{R}=$ is the regulator's perceived social pressure towards the promotion of innovation

$C_{R}=$ is the regulator's perceived control over the regulatory process towards the promotion of innovation

$w=$ are the parameters to be determined empirically

$+=$ indicates an algebraic sum

$\sim$ = suggests that willingness is expected to predict behaviour. 


\section{Understanding the willingness or resistance of firms to engage on innovation}

Similar to the above, this section proposes a set of definitions to explore and predict the conditions under which the firm would be more prone to engage in during innovation.

\subsection{Attitudes towards innovation}

As defined above, attitude is the degree to which people have a favourable or unfavourable evaluation or appraisal of a specific behaviour. In the realm of the firm, the attitude towards innovation can be defined as: an index of the degree to which the firm likes or dislikes (approves or disapproves of, agrees or disagrees with, etc.) any aspect arising from engagement in innovative activities. Each behavioural belief links specific behaviour to an outcome or an attribute that is valued positively or negatively. Thus, it can be expected that firms will tend to prefer behaviours believed to produce desirable consequences. The attitude towards a specific innovation results from the accumulated connotative load associated with the salient behavioural beliefs or relevant information regarding the implications of the planned innovation. The beliefs arise from two realities within the firm: the greater social, economic and environmental benefits and the economic consequences for the firm.

Examples of negative attitudinal salient beliefs are: a new technology is risky, it can be unreliable, costly and time-consuming to develop; there are no market opportunities, rights appropriability and patenting regimes, etc. Such beliefs imply negative connotations for negative outcomes. These beliefs can be expected to contribute to the formation of a negative attitude towards the engagement in innovation. A negative attitude is likely to prevent any engagement in innovative activities. With the perception of positive outcomes or in the presence of a positive attitude, the opposite outcomes can be expected. An index of attitude $\left(A_{F}\right)$ can be obtained, as shown in Equation (5), by multiplying the subjective evaluation $\left(e_{f i}\right)$ of each belief attribute by the strength $\left(b_{f i}\right)$ of each salient belief, with the resulting products summed over the $n$ salient beliefs.

$$
A_{F} \propto \sum_{i=1}^{n} b_{f i} e_{f i}
$$

where:

$A_{F}=$ is the firm's attitude towards the engagement in innovative activities

$b_{f i}=$ is the belief (subjective probability) that the engagement in innovation will lead to outcome $i$

$e_{f i}=$ is the evaluation of the outcome $i$ made by the firm's manager.

\subsection{Firm's normative beliefs and subjective norms}

In the case of a firm's behaviour, the subjective norm can be conceptualised as the social pressure or social norm that arises from the context in which the firm operates. Here, we can define the firm's perceived social norm $\left(N_{F}\right)$ as the importance that the firm's manager gives to different crucial referents to engage or not to engage in innovative activities. It results from the accumulated connotative load of normative beliefs that managers may hold. That is, it depends on how managers perceive the thinking of 
important referents within the firm about what the firm's behaviour should be (e.g., staff suggestions, shareholder expectations) and how they perceive external referents (e.g., behaviour of competitors, pace of technological innovation in the sector, customers' expectations, legal requirements, public perceptions, and industry standards and norms). As in the case of the regulators, it is made explicit here that the behaviour of the firm might be influenced by other actors or institutional factors than the regulator. It is assumed that those firms with high social pressure will be more willing to engage in innovative activities, as these will be perceived as necessary to maintain a competitive edge. However, such a perception may or may not reflect what the important referents really expect from, or think about the behaviour of the firm, or even reflect the real condition of the market. The sources of important referents might be the markets (competitors, pace of innovation, etc.); communities (local communities, shareholders, non-governmental organisations (NGOs), etc.) and the regulatory regimes in which the firm operates (international agreements and standards, regulatory bodies, etc.).

This index can be calculated by multiplying the strength of each normative belief $\left(n_{f j}\right)$ by the manager's (i.e., the firm's) motivation or perceived necessity to comply with, or follow the referent in question $\left(m_{f j}\right)$. The social norm is hypothesised to be directly proportional to the sum of the resulting products across the $n$ salient beliefs, as shown in Equation (6).

$$
N_{F} \propto \sum_{j=1}^{n} b_{f j} m_{f j}
$$

where:

$N_{F}=$ is the firm's perceived social norm

$b_{f j}=$ is the firm's normative belief concerning referent $j$

$m_{f j}=$ is the firm's motivation to comply with, follow or anticipate to the preferences (or behaviour) of referent $j$.

\subsection{Firm's perceived control over the innovation process}

Perceived behavioural control was defined above as the perceived ease or difficulty of performing the behaviour. In the context of the firm, innovation can be considered as a behaviour that, in many cases, is not under the volitional control of the manager. Perceived control over any innovation process $\left(C_{F}\right)$ is an index of the presence or absence of the requisite resources and opportunities to carry out innovative activities to achieve competitive edge. These beliefs may be based on past experience in innovation projects, second-hand information or any other factors that increase or reduce the perceived difficulty or feasibility of a specific innovation project. Overall, perceived control over the innovation process arises from the accumulated connotative load of beliefs with regard to the perceived ease or difficulty to achieve the planned outcome. Depending on the perceived control over technological (i.e., technological capabilities and opportunities) or organisational change (i.e., organisational learning, and networks and alliances to acquire new skills and knowledge), the willingness of the firm to innovate can be expected to be strong or weak. 
An index of the perceived control over the innovation process can be estimated by multiplying the control belief strength $\left(c_{f i}\right)$ by the perceived power $\left(p_{f i}\right)$ of the specific factor that facilitates or inhibits the performance of the action. The resulting product is summed across the $n$ salient beliefs as shown in Equation (7).

$$
C_{F} \propto \sum_{i=1}^{n} c_{f i} p_{f i}
$$

where:

$$
\begin{aligned}
C_{F} & =\text { is the firm's perceived control over the innovative activity } \\
c_{f i} & =\text { is the control belief strength } \\
p_{f i}= & \text { is the perceived power over particular control factors that facilitate or inhibit } \\
& \text { the conduction of an innovation. }
\end{aligned}
$$

Finally, as was the case for regulation, in order to integrate the above constructs, Equation (8) suggests that the firm's strategic or planned innovative behaviour is a function of the three indexes presented above. The form of the function of attitude, social norms and perceived control over innovation with the willingness to engage, and the performance of innovation, must be determined empirically.

$$
F \sim W_{F}=w_{1}+w_{2} A_{F}+w_{3} N_{F}+w_{4} C_{F}
$$

where:

$$
\begin{aligned}
F= & \text { is the overt behaviour, the engagement of the firm in a specific innovative } \\
& \text { activity } \\
W_{F}= & \text { is the firm's plan or intention to engage in innovation } \\
A_{F}= & \text { is the firm's attitude towards the engagement in innovative activities } \\
N_{F}= & \text { is the firm's perceived social norm concerning engagement in innovation } \\
C_{F}= & \text { is the firm's perceived control over the innovation process. }
\end{aligned}
$$

\section{Innovation and governance of change}

Experience in the fields of environment, public utilities and market regulation has demonstrated that in the regulatory game, interdependencies and power asymmetries have always existed (Nowotny, 1989; Ziegenhagen, 1986; Caillaud et al., 1988; Laffont and Tirole, 1991; 1993). Similarly, in innovation studies, the role of multi-actors and networks is assumed to determine the selection environment of innovations (Nahuis, 2005; Smits and Kuhlmann, 2004; Dieperink et al., 2004; Kuhlmann, 2001; Smits et al., 1995; Rothwell, 1992). The framework presented above gives an indication of what might be the behavioural drivers of different actors in specific situations. A wide variety of factors, depending on the type of innovation in question and the internal and external contexts of the firm and the policymaker, influence the governance and regulation process or trigger innovation. By applying the structural model presented above, we can systematically explore the determinants of governance dynamics towards innovation and behavioural change in the context of both the regulator and the firm. 
Many scenarios can be proposed. For example, a firm can be highly motivated to innovate by normative aspects of behaviour (i.e., by market, community or regulatory pressures). In addition, the firm might be able to exploit good economic opportunities in combination with producing laudable social outcomes. Taking into account only those aspects concerning attitudes and social norms, and discounting past experience and current control over the innovation process (i.e., economic resources, timing and capabilities) might lead to misleading conclusions. Another example is when a firm is highly motivated to innovate by attitudinal aspects of behaviour (e.g., economic opportunities and good appropriability conditions) coupled with good capabilities to innovate. Both of these aspects might be optimal, but normative aspects (e.g., community and regulatory pressures) might, nevertheless, hamper the innovative process. The cases of human cloning, Genetically Modified Organisms (GMOs) and co-generation of energy through the incineration of waste in the cement industry are good examples here.

Similarly, on the regulatory side, we might have a regulatory entity that perceives substantial economic, environmental and societal gains arising from specific innovations. This perception might be reinforced by strong community demands, while at the same time face strong opposition from industry, which might threaten political positions or be certain to engender fierce conflict in the short-term. These opposing forces may make the regulatory entity unwilling to engage in such a conflictive policy-making process or enforcement of a controversial regulation. In general, the governance outcome will arise from the interaction between regulators and firms mediated by the pre-conditions that determine their behaviours. In scenarios where there is a mismatch of the pre-conditions that determine the behaviours of these agents, we could expect a conflict of interests. In such conditions, innovative developments would be unlikely to occur.

Figure 1 shows the likely sources of mismatch in the agendas represented by the regulator and the interest of the firms at $t=0$ in the process of innovation governance. Figure 1 is intended to illustrate the model's major components as described in Sections 4 and 5. It aims to make explicit the idea that the behaviour of both actors, despite their different behavioural criteria - i.e., regulators aiming to promote innovation via regulatory instruments and the firm developing or adopting innovations - constitute different sides of the same coin, that is, governance of innovation and change and its potential outcomes. This is further discussed below.

Figure 1 Structural determinants of governance and regulation

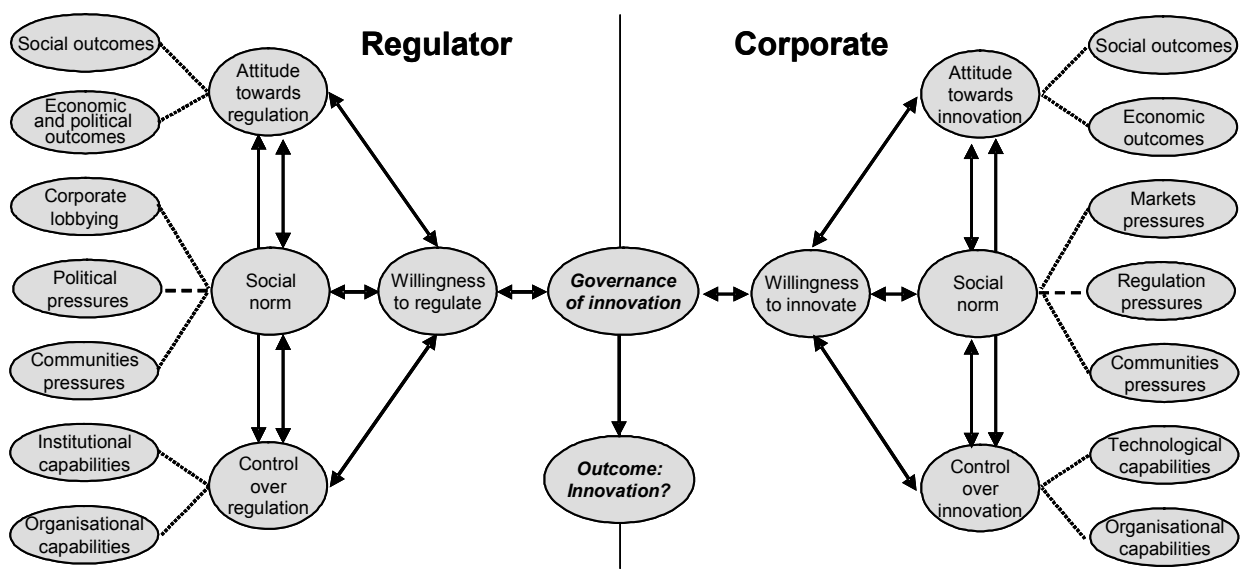




\section{Interdependencies between regulators and firms}

Exploring and identifying the determinants of both types of actors in the policy and regulatory process in specific situations and contexts can be challenging. It is even more problematic to conceptualise and describe the regulatory game in a dynamic fashion. The difficulty lies not only in attempting to define what are the drivers of the behaviour of each group of actors, but also in knowing how the actors interact. The problem lies in how to make explicit the interdependence of their behaviours despite their different intentions and their focus on different targets. The solution is to apply the definition of behavioural criterion given in Section 3 (i.e., action, target, context, and time) to each type of actor. This enables clear definitions of behaviours, and of the respective behavioural criterion for each of the actors involved in the regulatory process according to a common overall outcome of a specific policy problem. This is presented in Table 1 for three specific policy arenas: IPR, and environmental and innovation policies.

Table 1 shows that although the actors have different behavioural criteria, they still share the same high-order outcome in reference to a policy problem. For example, in the case of IPR, the policy issue normally is how to design and/or enforce an IPR regime that ensures the appropriation of benefits for pioneering inventions and innovations. There are different actors involved: those seeking protection and therefore promoting IPR, and those disregarding and avoiding the current IPR regime. All actors could have disparate time frames, scopes of influence and interests, but a final common higher-order outcome is to profit from an IPR regime, acting for or against it. The outcome at a given moment could vary for different players; some will be winners and others, losers.

In the case of the environment, the behaviours are mirror images, i.e., 'enforcement of regulations' versus 'compliance with or resistance to regulations' is expected to produce environmental protection (or failure of it) as an outcome. ${ }^{8}$ As in the case of IPR, both actors might have different behavioural criteria, but they are unified in a single policy issue by the final outcome of their interaction and respective behaviour.

Lastly, in the case of innovation policy, it is well known that two of the major outcomes assumed to arise from innovation - for policymakers and firms - are competitiveness and economic growth. Firms and regulators, as in the previous examples, might have different behavioural criteria, but their behaviours are directed towards a common outcome in a common policy arena. The regulator might be pursuing economic growth for society's benefit, while the firm more likely does it for its shareholders. The outcome might have a different scope and connotation for both actors, but will be fundamentally the same. From Table 1, we can conclude that people or institutions, while they might have different behavioural criteria at a higher-order level, aim for the same behavioural outcome. Thus, if it is possible to define common behavioural outcomes beyond the overt behaviours of the actors assumed to be acting interdependently, then the dynamics of their interdependence can be explored at the level of a higher-order behavioural outcome pursued by the target population with respect to a common issue or set of issues. In the next subsection, we describe how interdependence between regulators and regulators might occur. 
Table 1 Behavioural criteria and behavioural outcomes in diverse policy arenas






\subsection{The dynamics of regulation and governance of innovation}

In order to simplify the description of the interdependence of each actor, the mediator $W$ between behaviour and its determinant shown in Equations (4) and (8) in this exercise will be eliminated and the behaviours of the regulator and the regulatee are denoted by $R$ and $F$, respectively. ${ }^{9}$ In Sections 4 and 5 it was made explicit that the behaviour of both actors is dependent upon a variety of factors. Ceteris paribus, Figure 2 depicts the paths of influences in an interdependent dynamic of governance. The dark-grey path indicates paths of direct and indirect influences from regulators to regulatees. The paths $g_{R}, h_{R}$, and $m_{R}$ are the indirect effects and $f_{R}$ is the path of direct influences. Equations (9) and (10) denote the dependency paths between $R$ and $F$.

$$
\text { Where } \quad\left\{\begin{array}{l}
A_{F}=g_{R}(R) \\
N_{F}=h_{R}(R) \text { for } t=n-1, \\
C_{F}=m_{R}(R)
\end{array}\right.
$$

And vice versa, by following the light-grey path in $t=1$, we can anticipate some reactions and possible influences from regulatees to regulators. The paths $g_{F}, h_{F}$, and $m_{F}$ show the indirect effects and $f_{F}$ shows the path of direct influences.

$$
\text { Where }\left\{\begin{array}{l}
A_{R}=g_{F}(F) \\
N_{R}=h_{F}(F) \text { for } t=n, \\
C_{R}=m_{F}(F)
\end{array}\right.
$$

Figure 2 The dynamics of regulation and governance of innovation

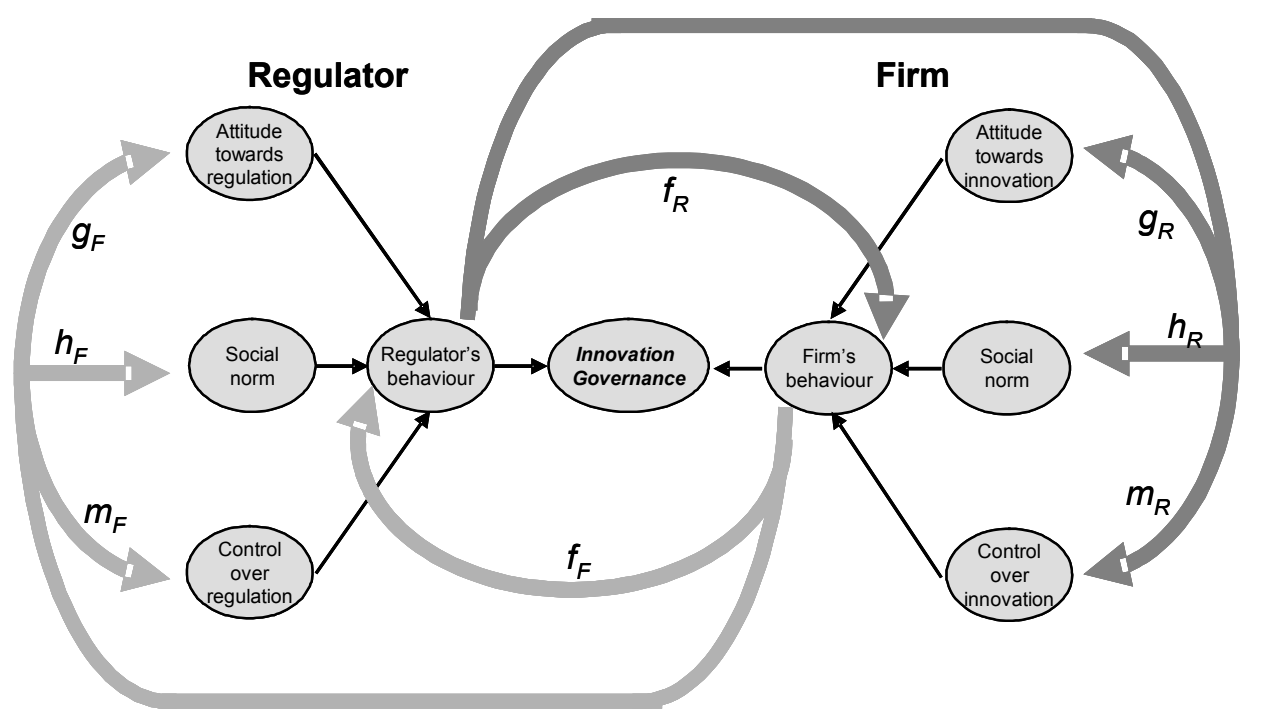

At $t=0$, both actors - regulators and firms - display only covert behaviour as they cannot identify the attitudes (A), the perceived social norms (N) and the perceived control (C) of the other. At this point, it is only possible to estimate indirect effects as both actors can 
only guess at the future behaviour of the other. At $t=1,2,3, \ldots, n$ both actors display overt behaviours that will have direct effects on the behaviour of the other in an interdependent fashion. Such interdependencies for $t=n$ and $t=n-1$ are described in Equation (11):

$$
\begin{gathered}
F_{1}=f\left(R_{0}\right) ; \Rightarrow R_{2}=g\left(F_{1}\right) ; \\
F_{3}=f\left(R_{2}\right) ; \Rightarrow R_{4}=g\left(F_{3}\right) ; \\
F_{5}=f\left(R_{3}\right) ; \Rightarrow R_{6}=g\left(F_{5}\right) ; \\
\vdots \\
\vdots \\
F_{n}=f\left(R_{n-1}\right) ; \Rightarrow R_{n+1}=g\left(F_{n}\right)
\end{gathered}
$$

For example, assuming the governance and regulatory process to start on the regulatory side, we can foresee a sequence of moves. In the first instance, in $t=0$, the regulator proposes a regulation based on past experience and motivated by awareness of certain issues (e.g., safety, environment, competitiveness, pricing, etc.) and the social pressures associated with them, plus acknowledgement of some of the benefits that the adoption (or development) of new technologies would bring for the economy and society. In $t=1$, the firm perceives the regulation as an outcome of the regulator's behaviour. The firm assesses the same issues that are assessed by the regulator and the possible consequences of investing in technical change for the firm. This could generate positive or negative attitudes depending upon the expected outcomes. Simultaneously, the firm perceives the overall market pressures and the power of the regulator to enforce the regulation, and assesses its motivation to comply with the perceived social norm.

Finally, the firm evaluates the timing, resources and capabilities required to carry out a specific innovation while gauging its capacity and resources to lobby for (or against) the proposed regulation. In $t=1$, the firm will react to the regulator's behaviour by complying with the regulation, seeking to negotiate better terms, opposing total resistance, etc. So we can expect that the behaviour of the firm in $t=1$, is a function of the regulator in $t=0$. The following stages in governance dynamics can be expected to follow until an agreement, compromise, stalemate or dominance of one player is reached in $t=n$, or until other forces come into play to motivate changes in the behaviour of both players.

The above describes something that is already accepted in the literature on regulation, that is, that there is some kind of interdependence between regulators and firms (Fenger and Klok, 2001; Caillaud et al., 1988; Laffont and Tirole, 1991; 1993; Nahuis, 2005). The question here is how do we detect interdependency, conflict and power asymmetry in a specific context and situation? Furthermore, is it possible to assess the degree of influence exerted by the regulator upon the firm, and vice versa? That is, can we determine which side is really leading the governance process? The answers to these questions will indicate the ability of regulatory institutions to lead institutional and technical change towards a desired societal goal. 


\section{Assessing the impact of regulation on innovation}

The previous section indicates the complexity of the interaction and potential sources of impacts upon the innovative behaviour of the firm. In this section, we introduce a method to link Equations (4) and (8) in a dynamic fashion to respond to the questions posed in the previous section. The model describing the interaction of firms and regulation across time is a modified version of the Lokta-Volterra model of competition between species. The models available in the literature allow for the dynamics of competition or mutualism between and within species. In these models, the rate of change and dominance between species is assumed to be a negative or positive linear function of population size (e.g., Coste et al., 1978; Pistorious and Utterback, 1995; Poggiale, 1998).

If we see the governance of innovation as a dynamic in two groups that pursue the realisation of their agendas and interest either by dominance or collaboration, the Lotka-Volterra model is appropriate to describe the dynamics of interdependence at the level of behaviour of actors $F$ and $R$. Building on competition and cooperation models, a modified model that allows for competition, cooperation and dominance between groups is proposed. The model hypothesises that for points of equilibrium $d F / d t=d R / d t=0$ the isoclines are concave functions of the behaviours of the actors involved in the game. Following the Lotka-Volterrra model of cooperation and competition, the dynamics of innovation governance and interdependence between firms and regulators as described in the previous section can be summarised as follows.

The impact of regulation on the innovative behaviour of firm $F$ can be expected to be proportional to the difference among three factors:

- The optimal innovative behaviour of $F$ as perceived by $R\left(\beta_{F} F\right) .{ }^{10}$

- $\quad$ Exogenous factors affecting $F\left(\alpha_{F} F\right)$.

- The difference in the power of both actors moderated by interaction with the regulator $\left[\gamma_{R F}\left(R_{n-1}-F_{n}\right)^{2}\right]$.

Similarly, the behaviour of the regulator $R$ would be:

- $\quad$ The optimal regulatory behaviour of $R$ as perceived by $F$.

- Exogenous factors affecting regulators $\left(\alpha_{R} R\right)$.

- The difference in the power of both actors moderated by interaction with the firm $\left[\gamma_{F R}\left(F_{n}-R_{n+1}\right)^{2}\right]$.

The innovation governance process will be characterised by collaboration and convergence towards a common goal or conflict and divergence towards different goals under the dominance of one of the actors. The general form that describes these dynamics is given by Equations (12) and (13):

$$
\begin{aligned}
& \frac{d F}{d t}=F\left[\beta_{F}-\alpha_{F} F-\gamma_{R F}\left(R_{n-1}-F_{n}\right)^{2}\right] \\
& \frac{d R}{d t}=R\left[\beta_{R}-\alpha_{R} R-\gamma_{F R}\left(F_{n}-R_{n+1}\right)^{2}\right]
\end{aligned}
$$


where:

$$
\begin{aligned}
\frac{d F}{d t}= & \text { behaviour of } F \text { considering the interdependence with } R \\
\frac{d R}{d t}= & \text { behaviour of } R \text { considering the interdependence with } F \\
\gamma_{R F}= & \text { rate of influence of } \mathrm{R} \text { upon actor } F\left(-1 \leq \gamma_{R F} \leq 1\right)^{11} \\
\alpha_{F}= & \text { rate of behavioural change of actor } F \text { in the face of exogenous factors } \\
& \left(\alpha_{F}>0\right) \\
\beta_{F}= & \text { rate of change in desirable innovative behaviour of } F \\
\beta_{R}= & \text { rate of change in desirable regulatory behaviour of } R \\
F= & \text { benchmark or desirable innovative behaviour of } F \text { as set by } R \\
R= & \text { benchmark or desirable innovative behaviour of } R \text { as set by } F \\
R_{n-1}= & \text { behaviour of } \mathrm{R} \text { as estimated in Equation }(8) \\
F= & \text { behaviour of } \mathrm{R} \text { at } t=n \text { estimated in Equation (4) } \\
R_{n+1}= & \text { behaviour of } \mathrm{R} \text { at } t=n+1 .
\end{aligned}
$$

The first value of $R_{n-1}$ is obtained empirically, and similarly $F_{n}$ should be estimated with Equation (4) and used in Equation (12). ${ }^{12}$ In the next iteration, the new value of $F$ should be used with Equation (13) as $F_{n}$. At this time the value of $R_{n+1}$ should be estimated with Equation (8). The coefficient $\gamma_{R F}$ determines the convexity of the isoclines, and $R_{n-l}, F_{n}$, $R_{n+1}, \beta_{F}$ and $\beta_{R}$ determine the changes in the isoclines along the axis $F$ and $R$. For $d F / d t=$ $d R / d t=0$ the equilibrium isoclines of Equations (12) and (13) are given by the respective graphics of the both isoclines as shown in Figure 3:

$$
\begin{aligned}
& F=\beta_{F}-\gamma_{R F}\left(R_{n-1}-F_{n}\right)^{2} \\
& R=\beta_{R}-\gamma_{F R}\left(F_{n}-R_{n+1}\right)^{2}
\end{aligned}
$$

The non-linear system proposed in Equations (12) and (13) offers the opportunity to analyse the effects of one actor upon the behaviour of the other (see Figures 3a, 3b). In addition, it enables the cycles of interaction between both actors, and the search for dynamic equilibriums to be examined, where the behaviour of both actors towards innovation is optimised. That is, the agendas of both actors coincide or compromise (see Figure 3c). From Figure 3, we can clearly infer that both actors can exert positive and negative influences on each other. It is obvious that after a critical point, a regulation intended to have a positive influence on the innovative behaviour of the firm can become a negative influence depending on the reaction of the firm itself. From Equations (14) and (15) we can say that if $F_{n}=R_{n-l}$, then $F=\beta_{F}$; and if $R_{n+l}=F_{n}$, then $R=\beta_{R}$, the maximum innovation capacity of the interdependent system regulator-firm occurs. That is, both political agendas match and converge towards a common goal (this situation is depicted in Figure 3c. In this situation the actors meet one another's expectations). 
Figure 3 Equilibrium isoclines for regulators and regulatees

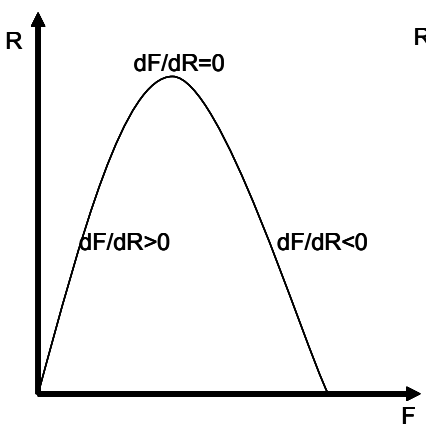

a)

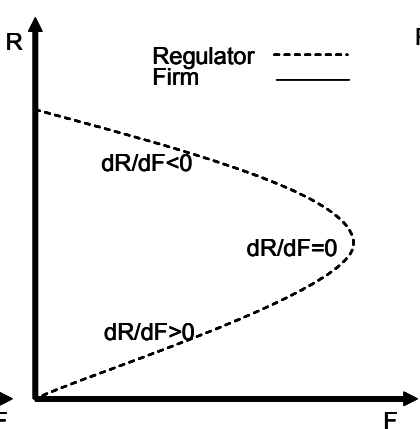

b)

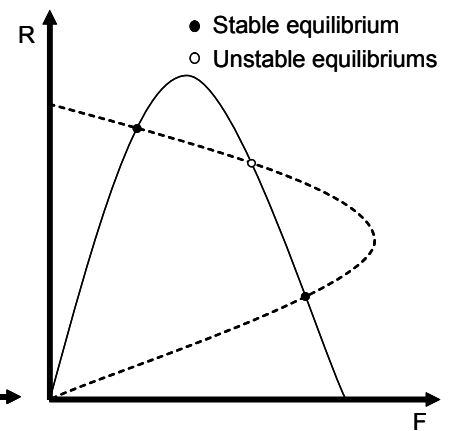

c)

In general, the literature reports three types of solutions for the non-linear system of Equations (12) and (13): the interaction between the two players (groups or species) tends to equilibrium, diverges to infinite or tends to a periodic orbit of alternate dominance of both actors or species considered (Chiang, 2004; Coste et al., 1978; Bradshaw and Moseley, 1998). There is ample evidence that within a system of two interdependent species, the system functions optimally benefiting both species when the system is in dynamic equilibrium (Tschirhart, 2000). As an analogy, from the literature on systems of innovations and recently on the new term 'open innovation', we know that for an innovation to succeed in the marketplace, from its invention to its diffusion, it is a necessary condition that the agendas and interests of the many actors involved must coincide. Despite some differences among actors, the myriad of interests converge towards a common interest (Watanabe et al., 2004). Given the three results observed empirically in the model proposed above, we are interested in the conditions in which the system converges towards or diverges from a situation of dynamic equilibrium. This can be achieved qualitatively by analysing the dynamics involved, using phase diagrams as depicted in Figure 3c. It is sufficient to find the signs of the rates of change for $d F / d R$ and $d R / d F$; the analysis of the four phases and the rate of change of both actors will indicate if the governance of innovation converges towards or diverges from dynamic equilibrium. Using Equations (12) and (13), it is possible to generate multiple governance scenarios. The scenarios will be contingent on changes in the main variables defined in Equations (4) and (8) and the parameters $\beta$ and $\gamma$ in Equations (14) and (15). In terms of the impact of regulation on the innovative behaviour of the firm, based on Figure $3 \mathrm{a}$, three scenarios of governance outcomes can be derived, and are used here as examples to illustrate the power analysis of the model proposed. They are depicted in Figure 4 with respect to governance under power asymmetry.

In Scenario (a) in Figure 4, when $\frac{d F}{d R}= \pm 1$, we can expect a dynamic of governance characterised either by collusion against change or collaboration towards change. Similar to a couple dancing together, in this scenario there is a quasi-synchrony between the actors. For any move or policy effort on the regulatory side, we can expect a proportional reaction from the firm. In the case of collusion, notwithstanding that all the other factors influencing the behaviours of the firms and regulators are conducive to change, this 
change might be delayed, or not occur at all. In this scenario, there is no concurrence between societal goals and the regulators' and firms' agendas. Here, a situation of corruption between regulators and firms can be envisaged. Conversely, in a situation of collaboration towards change, the values, beliefs and motivations of regulators and firms match and converge towards desirable societal goals. Any positive proposition made by the regulators receives a positive response of collaboration from the firms, in the interests of a common goal of behavioural change. The sources and situations of collusion or collaboration can be defined by comparing the indexes of attitudes, social norms and perceived control of both group of actors as defined in Sections 3 and 4 above.

Figure 4 Scenarios of innovation governance outcomes

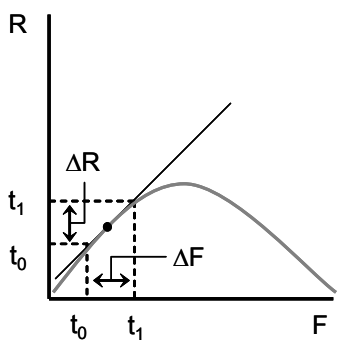

a)

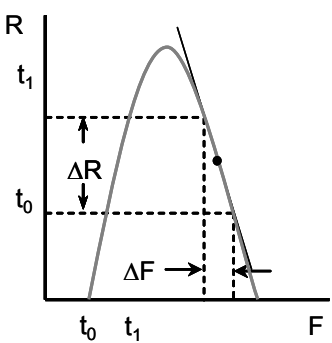

b)

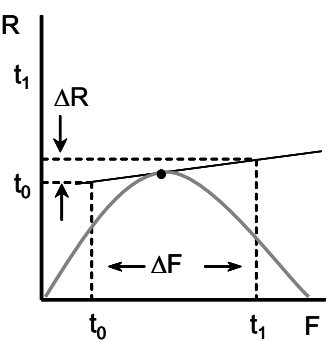

c)

In Scenario (b), when $-1<\frac{d F}{d R}<0$, we can expect that the process of governance will not converge towards the desired innovations. This occurs because factors other than regulation that might influence the behaviour of the firm (e.g., market signals, economic opportunities, feasibility of technological and organisational change, perceived environmental risks, etc.) present conditions not conducive to engagement in innovative activities. Thus, the stimuli are not great enough for the firms to engage in innovative activities. Figure $4 \mathrm{~b}$ indicates that any large regulatory and policy effort is likely to generate far less than proportional effects on the current behaviour of the firm.

In Scenario (c), in contrast to (a) and (b), when $0<\frac{d B_{F}}{d B_{R}}<1$, we can expect a dynamic of positive governance whereby the factors influencing the behaviour of both actors are conducive to the promotion of innovation. Figure (4c) indicates situations in which there is a strong power asymmetry leaning towards the regulatory side. Here, a minimum regulatory effort produces a major change in the behaviour of the firm towards innovation. Provided that there are clear capabilities and visions driving behavioural change towards a specific innovation, we can expect that governance will converge towards the success of policies promoting innovation. 


\section{Discussion}

The framework presented above introduced a method to explore the limits and the capacity of a political system to promote innovation and change based on the assessment of the sources of the resistance to change of the social and economic actors. The ultimate aim of this paper was to propose a framework that enables the generation of an inventory of the possible combinations of factors that might induce firms to innovate in specific contexts and result in the design of appropriate regulations to promote innovation. In relation to the promotion of innovation, the effectiveness of government interventions here is seen as contingent on the phenomena of interdependence and power asymmetries between the regulators and the firm. The paper has proposed a set of definitions that enables assessment of the conditions under which firms and regulators might be more likely to engage in innovation. This assessment can be done in static or dynamic fashions. First, taking a static approach it is possible to assess causalities between innovation and its hypothetical drivers taking only one side of the model at a time. In this case in order to find the optimal mix of innovation drivers for a specific situation, Equations (4) and (8) should be optimised with respect to $R$ or $F$ (see Montalvo, 2006). Second, if taking a dynamic approach, the assessment and projection of systemic divergence or convergence towards a common policy outcome can be done. The test would consist of finding a set of conditions for $A_{F}, N_{F}, C_{F}, A_{R}, N_{R}$, and $C_{R}$ - via an iterative game - that will make the system of actors described in Equations (12) and (13) achieve a desirably policy goal. Last, the assessment power asymmetries between actors can be done in a complementary fashion by analysing differences and similarities between the indexes $C_{F}$, and $C_{R}$ and their relationships with $A_{F}, N_{F}, C_{F}, A_{R}$ and $N_{R}$, and by calculating the elasticity behaviour to gauge if the relative influences of one actor on the other are less or more than proportional (see Figure 4 above).

Although this paper has focused on the most basic corporate governance mechanism that exists outside the firm - that is, the regulations that are intended to govern the behaviour of the firm - in a broader sense, the model proposed can be conceptualised as a dynamic structural theory of inter-group interaction. The paper considers the corporate body and the regulators as the main actors in the governance of change and the innovation process. In reality, the dynamic is much more complex than an interaction between two actors. Generally, multiple stakeholders are involved in the governance process (e.g., shareholders, block-holders, the board of directors, NGOs and pressure groups, competitors in the market, communities and regulators). The salience and importance of all players at a given moment may vary.

The model proposed provides the opportunity to substitute for the two main actors in the governance game or include more players in the equation. For the simultaneous modelling of several actors, further research needs to be conducted. Recent advances in the form of 'replicator dynamics' indicate the way forward to develop more comprehensive models (see Gafiychuk and Prykarpatsky, 2004; Miękisz, 2005; Alboszta and Miękisz, 2004). This would provide, for example, a tool to gauge the influence of diverse actors in the behaviour of the corporate actor, while allowing for assessment of which party is more likely to be driving the governance process. Similarly, this would enable us to gauge the relative effect of regulations with respect to many other factors influencing the innovative behaviour of the firm, thus providing insights on the likely outcomes of the governance game. Finally, by tracking back the factors that affect both the regulators' and firms' innovative behaviours, it is possible to simulate the conditions 
under which the desired innovation can be best promoted, or to clearly show that in certain situations, systems are 'self-organised' and there is little room to efficiently promote innovation, given the diversity of conflicts of interests, and the institutional and technological rigidities of both regulators and regulatees.

\section{References}

Aglietta, M. (2002) 'The international monetary system', in R. Boyer and Y. Saillard (Eds.) Regulation Theory: The State of the Art, London: Routledge, pp.64-72.

Ajzen, I. (1985) 'From intentions to actions: a theory of planned behaviour', in J. Kuhl and J. Beckmann (Eds.) Action-Control: From Cognition to Behaviour, Heidelberg: Springer, pp.11-39.

Ajzen, I. (1988) Attitudes, Personality, and Behaviour, Chicago: Dorsey Press.

Ajzen, I. (1991) 'The theory of planned behaviour', Organizational Behaviour and Human Decision Process, Vol. 50, pp.179-211.

Ajzen, I. (1996) 'The moderating effects of attitude in decision making', in P.M. Gollwitzer and J.A. Bargh (Eds.) The Psychology of Action: Linking Cognition and Motivation to Behaviour, New York: Guilford Press.

Ajzen, I. and Krebs, D. (1994) 'Attitude and measurement: implications for survey research', in I. Borg and P. Mohler (Eds.) Trends and Perspectives in Empirical Social Research, New York: Walter de Gruyter, pp.250-262.

Alboszta, J. and Miękisz, J. (2004) 'Stability of evolutionarily stable strategies in discrete replicator dynamics with time delay', Journal of Theoretical Biology, Vol. 231, pp.175-179.

Armitage, C.J., Conner, M., Loach, J. and Willetts, D. (1999) 'Different perceptions of control: applying an extended theory of planned behaviour to legal and illegal drug use', Basic and Applied Social Psychology, Vol. 21, No. 4, pp.301-316.

Baldwin, R. and Cave, M. (1999) Understanding Regulation: Theory, Strategy and Practice, Oxford: Oxford University Press.

Bamberg, S. (1999) 'Pro-environmental behaviour - a question of moral or right incentives?', Zeitschrift fur Sozialpsycologie, Vol. 30, No. 1, pp.57-76.

Bamberg, S. and Schmidt, P. (1997) 'Theory driven evaluation of an environmental policy measure: using the theory of planned behaviour', Zeitschrift fur Sozialpsycologie, Vol. 28, No. 4, pp.280-297.

Blind, K. (2004) 'New products and services: analysis of regulations shaping new markets', Brussels: Report to DG Enterprise/Innovation Policy Unit, in the Framework of the Innovation/SMEs programme, Part of the Fifth Research Framework Programme.

Boldero, J. (1995) 'The prediction of household recycling of newspapers: the role of attitudes, intentions, and situational factors', Journal of Applied Social Psychology, Vol. 25, No. 5, pp.440-462.

Bourreau, M. and Dogan, P. (2001) 'Regulation and innovation in the telecommunications industry', Telecommunications Policy, Vol. 25, pp.167-184.

Boyer, R. and Saillard, Y. (Eds.) (2002) Regulation Theory: The State of the Art, London: Routledge.

Bradshaw, A.T. and Moseley, L.L. (1998) 'Dynamics of competing predator-prey species', Physica A, Vol. 261, pp.107-114.

Bruneau, J.F. (2004) 'A note on permits, standards, and technological innovation', Journal of Environmental Economics and Management, Vol. 48, pp.1192-1199.

Caillaud, B., Guesnerie, R., Rey, P. and Tirole, J. (1988) 'Government intervention in production: a review of recent contributions', Rand Journal of Economics, Vol. 19, pp.1-26. 
Carlsmith, J.M., Ellsworth, P.C. and Aroson, E. (1976) Methods of Research in Social Psychology, Reading, MA: Addison Wesley.

Cheung, S.F., Chan, D.K.S. and Wong, Z.S.Y. (1999) 'Re-examining the theory of planned behaviour in understanding wastepaper recycling', Environment and Behaviour, Vol. 31, No. 5, pp.587-612.

Chiang, A.C. (2004) Fundamental Methods of Mathematical Economics, McGraw-Hill.

COM (2004) 'Stimulating technologies for sustainable development: an environmental technologies action plan for the European Union, communication from the commission to the planned behaviour: an examination of the cognitive mediation of past behaviour', Journal of Applied Psychology, Vol. 29, No. 8, pp.1676-1704.

Conner, M. and Armitage, C.J. (1998) 'Extending the theory of planned behavior: a review and avenues for further research', Journal of Applied of Applied Social Psychology, Vol. 28, No. 15 , pp.1429-1464.

Coste, J., Peyraud, J., Coullet, P. and Chenciner, A. (1978) 'About the theory of competing species', Theoretical Population Biology, Vol. 14, pp.165-184.

Dewick, P. and Miozzo, M. (2002) 'Sustainable technologies and the innovation-regulation paradox', Futures, Vol. 34, pp.823-840.

Dieperink, C., Brand, I. and Vermeulen, W. (2004) 'Diffusion of energy-saving innovations in industry and the built environment: Dutch studies as inputs for a more integrated analytical framework', Energy Policy, Vol. 32, No. 6, pp.773-784.

Doll, J. and Ajzen, I. (1992) 'Accessibility and stability of predictors in the theory of planned behavior', Journal of Personality and Social Psychology, Vol. 63, No. 5, pp.754-765.

Drahos, P. and Maher, I. (2004) 'Innovation, competition, standards and intellectual property: policy perspectives from economics and law', Information Economics and Policy, Vol. 16, pp.1-11.

Faulkner, A. and Kent, J. (2001) 'Innovation and regulation in human implant technologies: deloping comparative approaches', Social Science and Medicine, Vol. 53, pp.895-913.

Fenger, M. and Klok, P.J. (2001) 'Interdependency, beliefs, and coalition behaviour: a contribution to the advocacy coalition framework', Policy Sciences, Vol. 34, pp.157-170.

Fishbein, M. and Ajzen, I. (1975) Belief, Attitude, Intention, and Behavior: An Introduction to Theory and Research, Reading, MA: Addison-Wesley.

Fishbein, M. and Ajzen, I. (Eds.) (1980) Understanding Attitudes and Predicting Social Behaviour, Englewood Cliffs, NJ: Prentice Hall.

Fishbein, M., Ajzen, I. and McArdle, J. (1980a) 'Changing the behaviour of alcoholics: effects of persuasive communication', in I. Ajzen and M. Fishbein (Eds.) Understanding Attitudes and Predicting Social Behaviour, Englewood Cliffs, NJ: Prentice Hall, pp.218-242.

Fishbein, M., Jaccard, J.J., Davison, A.R., Ajzen, I. and Loken, B. (1980b) 'Predicting and understanding family planning behaviours: beliefs, attitudes and intentions', in I. Ajzen and M. Fishbein (Eds.) Understanding Attitudes and Predicting Social Behaviour, Englewood Cliffs, NJ: Prentice Hall, pp.130-147.

Gafiychuk, V.V. and Prykarpatsky, A.K. (2004) 'Replicator dynamics and mathematical description of multi-agent interaction complex systems', Journal of Nonlinear Mathematical Physics, Vol. 11, No. 1, pp.113-122.

Gollwitzer, P.M. and Bargh, J.A. (Eds.) (1996) The Psychology of Action: Linking Cognition and Motivation to Behaviour, New York: Guilford Press.

Greene, D.L. (1998) 'Why CAFÉ worked', Energy Policy, Vol. 26, No. 8, pp.595-613.

Griffin, R.J., Dunwoody, S. and Neuwirth, K. (1999) 'Proposed model of the relationship of risk information seeking and processing to the development of preventive behaviours', Environmental Research, Vol. 80, No. 2, pp.230-245.

Guttman, L. (1954) 'A new approach to factor analysis: the radex', in P.F. Lazarsfeld (Ed.) Mathematical Thinking in the Social Sciences, Glencoe, IL: Free Press. 
Harland, P., Staats, H. and Wilke, H.A.M. (1999) 'Explaining pro-environmental intention and behaviour by personal norms and the theory of planned behaviour', Journal of Applied Social Psychology, Vol. 29, No. 12, pp.2505-2528.

Harrison, D.A., Mykytyn, P.P. and Riemenschneider, C.K. (1997) 'Executive decisions about adoption of information technology in small business: theory and empirical tests', Journal Systems Research, Vol. 8, No. 2, pp.171-195.

Heyes, A.G. and Heyes, C.L. (1999) 'Corporate lobbying, regulatory conduct and the Porter hypothesis', Environmental and Resources Economics, Vol. 13, No. 2, pp.209-218.

Jonas, D. (1996) 'Safety, regulation and innovation in the food sector', Current Opinion in Biotechnology, Vol. 7, pp.262-264.

Jonas, K. and Doll, J. (1996) 'A critical evaluation of the theory of reasoned action and the theory of planned behaviour', Zeitschrift für Sozialpsychologie, Vol. 27, No. 1, pp.18-31.

Kuhlmann, S. (2001) 'Future governance of innovation policy in Europe - three scenarios', Research Policy, Vol. 30, pp.953-976.

Laffont, J.J. and Tirole, J. (1991) 'The politics of government decision-making: a theory of regulatory capture', Quarterly Journal of Economics, Vol. 106, pp.1089-1127.

Laffont, J.J. and Tirole, J. (1993) A Theory of Incentives in Procurement and Regulation, Cambridge, MA: MIT Press.

Lam, S.P. (1999) 'Predicting intentions to conserve water from the theory of planned behaviour, perceived moral obligation, and perceived water right', Journal of Applied Social Psychology, Vol. 29, No. 5, pp.1058-1071.

Lynne, G.D., Casey, C.F., Hodges, A. and Rahmani, M. (1995) 'Conservation technology adoption decisions and the theory of the planned behaviour', Journal of Economic Psychology, Vol. 16, No. 4, pp.581-598.

Metselaar, E.E. (1997) Assessing the Willingness to Change - Construction and Validation of the Dinamo, Amsterdam: Faculty of Psychology and Pedagogy, University of Amsterdam.

Miękisz, J. (2005) 'Equilibrium selection in evolutionary games with random matching of players', Journal of Theoretical Biology, Vol. 232, pp.47-53.

Montalvo, C. (2002) Environmental Policy and Technological Innovation: Why do Firms Adopt or Reject New Technologies?, Cheltenham, UK and Northampton, MA: Edward Elgar.

Montalvo, C. (2006) 'What triggers change and innovation', Technovation (available online at Elsevier science@direct since December 2004).

Nahuis, R. (2005) 'The politics of innovation: self-service on the Amsterdam trams', Technology in Society, Vol. 27, No. 2, pp.229-241.

Nowotny, K. (1989) 'The economics of public utility regulation', in K. Nowotny, D.B. Smith and H.B. Trebing (Eds.) Public Utility Regulation: The Economic and Social Control of Industry, Boston: Kluwer, pp.9-27.

Nowotny, K., Smith, D.B. and Trebing, H.B. (Eds.) (1989) Public Utility Regulation: The Economic and Social Control of Industry, Boston: Kluwer.

OECD (1985) Environmental Policy and Technical Change, Paris: OECD.

Pavitt, K. (1998) 'The inevitable limits of EU R\&D funding', Research Policy, Vol. 27, pp.559-568.

Pistorious, C.W.I. and Utterback, J.M. (1995) 'The death knell of mature technologies', Technological Forecasting and Social Change, Vol. 50, pp.215-233.

Poggiale, J.C. (1998) 'From behavioural to population level: growth and competition', Mathematical and Computational Modelling, Vol. 27, No. 4, pp.41-49.

Rotemberg, J.J. and Saloner, G. (2000) 'Visionaries, managers, and strategic direction', RAND Journal of Economics, Vol. 31, No. 4, pp.693-716.

Rothwell, R. (1992) 'Industrial innovation and government environmental regulation: some lessons from the past', Technovation, Vol. 12, No. 7, pp.447-458. 
Sabatier, P.A. (1999) Theories of the Policy Process, Boulder: Westview Press.

Sand, I.J. (1998) 'Understanding the new forms of regulation', European Law Journal, Vol. 4, No. 3, pp.271-293.

Sarver, Jr., V.T. (1983) 'Ajzen and Fishbein's “Theory of reasoned action”: a critical assessment', Journal for the Theory of Social Behaviour, Vol. 13, pp.155-163.

Smits, R. and Kuhlmann, S. (2004) 'The rise of systemic instruments in innovation policy', International Journal of Foresight and Innovation Policy, Vol. 1, Nos. 1-2, pp.4-32.

Smits, R., Leijten, A. and Hertog, D.P. (1995) 'Technology assessment and technology policy in Europe: new concepts, new goals and new infrastructures', Policy Science, Vol. 28, pp.271-299.

Sparrow, M.K. (2000) The Regulatory Craft, Washington: Brookings Institution Press.

Stewart, R. (1994) 'Environmental regulation and international competitiveness', Yale Law Journal, Vol. 103, pp.2039-2022.

Sutton, S. (1998) 'Predicting and explaining intentions and behavior: How well are we doing?', Journal of Applied of Applied Social Psychology, Vol. 28, No. 15, pp.1317-1338.

Taylor, S. and Todd, P.A. (1995) 'Understanding information technology usage: a test of competing models', Information Systems Research, Vol. 6, No. 2, pp.144-176.

Taylor, S. and Todd, P.A. (1997) 'Understanding the determinants of consumer composting behaviour', Journal of Applied Social Psychology, Vol. 27, No. 7, pp.602-628.

Terry, D.J. (1993) 'Self-efficacy expectancies and the theory of the reasoned action', in D.J. Terry, C. Gallois and M. McCamish (Eds.) The Theory of Reasoned Action: Its Application to AIDS - Preventive Behaviour, London: Penguin.

Tschirhart, J. (2000) 'General equilibrium of an ecosystem', Journal of Theoretical Biology, Vol. 203, pp.13-32.

Van Ryn, M. and Vinokur, A. (1992) 'How did it work? An examination of the mechanisms through which a community intervention influenced job-search behaviour among an unemployed sample', American Journal of Community Psychology, Vol. 33, pp.793-802.

Vidal, F. (2002) 'International regimes', in R. Boyer and Y. Saillard (Eds.) Regulation Theory: The State of the Art, London: Routledge, pp.108-114.

Watanabe, C., Kondo, R., Ouchi, N. and Wei, H. (2004) 'A substitution orbit of competitive innovations', Technological Forecasting and Social Change, Vol. 71, pp.365-390.

Wehn de Montalvo, U. (2003) Mapping the Determinants of Spatial Sata Sharing, Oxford: Ashgate Publishing.

Xu, X.P. (1999) 'Do stringent environmental regulations reduce the international competitiveness of environmentally sensitive goods? A global perspective', World Development, Vol. 27, No. 7, pp.1215-1226.

Ziegenhagen, E.A. (1986) The Regulation of Political Conflict, New York: Praeger.

\section{Notes}

1 A complete exposition of the theory can be found in Ajzen (1985; 1988; 1991). Critical analyses of the TPB can be found in Sarver (1983), Jonas and Doll (1996) and Sutton (1998).

2 The connotative meaning of a concept includes all of its suggestive or implicit significance. That is, the concept or object has significance only by association (see Carlsmith et al., 1976).

3 Examples of empirical testing in diverse areas of policy intervention can be found in: Fishbein et al. (1980a-b), Terry (1993), Van Ryn and Vinokur (1992), Armitage et al. (1999), Lynne et al. (1995), Taylor and Todd (1995; 1997), Harrison et al. (1997), Wehn de Montalvo (2003), Harland et al. (1999), Bamberg (1999), Griffin et al. (1999), Lam (1999), Boldero (1995), Cheung et al. (1999), Bamberg and Schmidt (1997) and Montalvo (2002). 
4 Examples of the methods used to design the necessary questionnaires to apply the model presented here, and the tests used to validate the data sets can be found in Metselaar (1997), Montalvo (2002) and Wehn de Montalvo (2003).

5 The appropriateness of using the same model to explore the behaviour of entrepreneurs in a small organisation (single decision-maker) and decision-makers operating in larger and more complex organisations has been discussed in Montalvo (2002, pp.114-115). The basic premise is that senior officers in the case of regulators (senior managers in the case of firms) are entrusted with the interests of their organisations and are best positioned to express the preferences and planned behaviour of their organisations. Thus, for empirical studies, the perceptions and judgements of the senior decision-makers are considered the best proxy for the preferences of institutions, such as firms and regulatory agencies.

6 An exposition of the complete method to explore beliefs, questionnaire protocol development and application, as well as the validation of method and theory underlying the basic model used in this paper, can be found in Montalvo (2002), Wehn de Montalvo (2003) and Ajzen (1988).

7 The linearity of the equation is well established in the literature (see Montalvo, 2006 forthcoming; Ajzen, 1991; Cheung et al., 1999; Harland et al., 1999; Taylor and Todd, 1995).

8 A mirror gives us back the perfect opposite image.

9 This assumption is based on a considerable body of empirical evidence which shows that at least intentions, plans and goals are highly correlated with behaviour (see Ajzen, 1991; Doll and Ajzen, 1992; Ajzen and Krebs, 1994; Sarver, 1983; Conner and Armitage, 1998; Jonas and Doll, 1996; Sutton, 1998).

10 This could be a maximum or a minimum depending on the policy issue or overall goal. This is the benchmark against which all other effects should be subtracted. In other applications of Lotka-Volterra type models, the first parameter of the equation is the maximum level that the dependent variable can reach under optimal conditions (i.e., carrying capacity, market share, population size, etc.). In some situations, this component in the model could be interpreted as the behaviour of $F$ in the absence of $R$, and conversely. In this case, the nature of $R_{n}$ and $F_{n}$ should be reconsidered.

11 The rate of interaction can take different meanings depending on the situation. It can be seen as a coefficient of aggressiveness-competence or mutualism-cooperation.

12 To see the methods of empirical estimation of the initial values of $R$ and $F$ in detail, see Montalvo (2002). 